\title{
EL DERECHO SUPLETORIO DEL CONTRATO DE SERVICIOS EN EL CÓDIGO CIVIL CHILENO. INSUFICIENCIA DE LAS REGLAS DEL MANDATO Y DEL ARRENDAMIENTO*
}

[The service contract's default Law in the Civil Code of Chile. The insufficiency of the rules of commission and lease]

\section{María Graciela BRANTt ZuMARÁN** Claudia MejÍ́As Alonzo***}

\begin{abstract}
RESUMEN
El presente trabajo estudia la conformación del derecho supletorio del contrato de servicios en el Código civil chileno a partir de dos modelos de frecuente celebración: el de servicios profesionales y el de ejecución de una obra material. Para ello se revisan las diversas normas del contrato de arrendamiento y del mandato -que aparecen como las disposiciones especiales posiblemente aplicables a dicho contrato atípico- en lo referido a dos aspectos relevantes: el contenido de las obligaciones y los
\end{abstract}

\begin{abstract}
This article studies the establishment of the supplementary law of the contract for the provision of services in the Chilean Civil Code on the basis of two frequently used models: professional services and the performance of a material work. To do this, two relevant aspects of the different norms of the lease contract and the power of attorney -that are the special stipulations likely applicable to said atypical contract: the substance of the obligations and the remedies regarding non-fulfilment, to evidence that they
\end{abstract}

Recibido el 1 de marzo y ACEPTADO el 15 de junio de 2016

* El presente artículo forma parte de la ejecución del Proyecto Fondecyt Regular No 1160469, del que las autoras son investigadora y co-investigadora respectivamente.

** Profesora Adjunta de derecho civil de la Pontificia Universidad Católica de Valparaíso.

*** Profesora Adjunta de derecho civil de la Pontificia Universidad Católica de Valparaíso. 
remedios por el incumplimiento, para demostrar que no permiten configurar un régimen supletorio propio y que, fundamentalmente, se remiten o reiteran las reglas generales del Libro IV de dicho cuerpo normativo, quedando pendiente definir si tales normas son idóneas para enfrentar las particularidades de estos contratos.

\section{Palabras clave}

Contrato de servicios - derecho supletorio - arrendamiento - mandato do not allow for the establishment of an inherent supplementary regime and that they basically refer to or repeat the general rules of Book IV of said regulatory body, the definition whether said norms are suitable to face the features of these contracts remaining pending.

\section{KEYWORDS}

Contract for rendering services supplementary Law - lease - power of attorney

\section{INTRODUCCIÓN}

Una afirmación recurrente en los trabajos, en materia de obligaciones y contratos, es la creciente importancia de los contratos de servicios en el tráfico jurídico ${ }^{1}$. A partir del desarrollo económico experimentado en las últimas décadas, han proliferado necesidades de la más diversa naturaleza, las que son satisfechas a través de la prestación de múltiples servicios, inexistentes o escasamente relevantes con antelación y que van más allá de los tradicionales servicios profesionales que pueda prestar un médico, abogado o arquitecto, es lo que acontece por ejemplo, con las asesorías computacionales o informáticas, de catering, de viaje combinado, asesoría de imagen, de espectáculos de diverso contenido, de spa y esparcimiento en general, de transporte, de asistencia técnica, de publicidad, de reparación, etc. Asimismo, el avance en el ámbito industrial y en los procesos productivos ha conducido a que muchas actividades que tradicionalmente se realizaban al interior de cada empresa pasen a ser ejecutadas por terceros ${ }^{2}$, en el contexto del fenómeno denominado externalización, que precisamen-

1 Barros Bourie, Enrique, Los contratos de servicios ante la doctrina general del contrato: la virtualidad analógica de las reglas del mandato, en ELORRIAGA, Fabián (editor), Estudios de Derecho Civil VII (Santiago, Abeledo Perrot, 2012) pp. 326-329. Rodríguez Pinto, María Sara, Incumplimiento y exoneración de responsabilidad en los contratos de servicios, en GUZMÁN BRITO, Alejandro (editor), Estudios de derecho civil III (Santiago, LegalPublishing, 2008), pp. 503-517. PeŃaIlillo, Daniel, Obligaciones (Santiago, Editorial Jurídica de Chile, reimp. 2011), pp. 40-43, 201.

2 Cfr. Scantanelli, Néstor, El comercio de servicios. Cuestiones principales desde 
te se ha desarrollado con ocasión de los servicios. Así lo comprueban las tareas de alimentación, aseo o seguridad al interior de las empresas, que en la mayoría de las ocasiones son encargadas a terceros especializados en la prestación de tales servicios.

De esta forma, como ha destacado en nuestro país el profesor Barros ${ }^{3}$, la relevancia histórica de los intercambios de cosas ha cedido protagonismo a las obligaciones que envuelven la prestación de un servicio. Se trata de un escenario, sin embargo, muy diverso al que enfrentó nuestro legislador civil. En efecto, a la época de entrada en vigencia de nuestro Código civil la economía se caracterizaba por intercambios sencillos que permitían el desarrollo de una sociedad predominantemente agrícola. Ello se refleja en la regulación del Código civil en materia de obligaciones, en la que prevalece notoriamente el interés del legislador por las obligaciones de dar, en particular, especies o cuerpos ciertos y, en menor medida, géneros, fundamentalmente dinero ${ }^{4}$. Por la misma razón la compraventa constituye el modelo sobre el que se construyó la doctrina del contrato en general. Esto por tratarse de la forma más frecuente de intercambio ${ }^{5}$, de una cosa por una suma de dinero.

Los contratos de servicios, en cambio, generan una obligación de hacer, la que a su vez puede subsumirse en la clasificación de obligaciones de medio o de resultado, atendida la conducta que debe desplegar el deudor; aspecto que resulta relevante en la determinación de la configuración de la prestación y, por ende, en el cumplimiento e incumplimiento contractual ${ }^{6}$.

una perspectiva latinoamericana, en Revista Jurídica de Buenos Aires I-II-III (1997) p. 156. El autor se refiere a este fenómeno como "out sourcing".

${ }^{3}$ Barros Bourie, Enrique, cit. (n.1), p. 326.

${ }^{4}$ En la doctrina nacional por todos: VIDAL Olivares, Álvaro, El incumplimiento de obligaciones con objeto fungible y los remedios del acreedor afectado. Una relectura de las disposiciones del Código civil sobre incumplimiento (2007), ahora en VIDAL Olivares, Álvaro, Incumplimiento contractual, resolución de indemnización de daños (Bogotá, Editorial Universidad del Rosario, 2010), pp. 137 y ss.; PeñAilillo, Daniel, cit. (n.1), pp. 40- 41. En la doctrina española: Moreno Quesada, Bernardo, Problemática de las obligaciones de hacer, en Revista de Derecho Privado (1976), pp. 467468. Díez-Picazo, Luis, Fundamentos de Derecho Civil Patrimonial (6a edición, Madrid, Editorial Civitas, 2008), II, pp.71-73. Morales Moreno, Antonio Manuel, La evolución del concepto de obligación en el derecho español (2007), ahora MORALES Moreno, Antonio Manuel, La modernización del derecho de obligaciones (Madrid, Editorial Aranzandi, 2006), pp. 21 y ss. Villanueva Lupión, Carmen, Los Servicios como objeto de tráfico jurídico (Madrid, Editorial la Ley, 2009), pp. 105-106. En la doctrina italiana, AMORTH, Giorgio, Errore e inadempimento nel contratto (Milano, Giufrè, 1967), pp. 99-100.

5 Barros Bourie, Enrique, cit. (n.1), p. 325.

${ }^{6}$ La doctrina nacional ha empleado la clasificación de obligaciones de medios y 
Como es sabido, se entiende por obligaciones de resultado aquellas en que la prestación comprende la concreción de una opus, esto es, una obra nueva o inexistente previamente, cuya verificación es lo que satisface el interés del acreedor. Por su parte, tratándose de las obligaciones de medio, el deudor compromete la realización de una conducta o actividad que debe sujetarse a las reglas de una determinada ciencia, arte o técnica, sin garantizar un resultado en particular al acreedor, cuyo interés resulta satisfecho por el solo despliegue de la referida conducta, que agota el contenido de la prestación ${ }^{7}$. En el terreno de los contratos de servicios la doctrina ha afirmado indistintamente la prevalencia de una u otra $^{8}$, sin embargo, como

resultado para efectuar un distingo en materia de responsabilidad civil. En las obligaciones de medios, la actuación que debe desplegar el deudor equivale a un actuar diligente, identificándose su no obtención con un actuar culposo, de manera que la culpa no podría disociarse de la noción misma de incumplimiento, y en tal caso la responsabilidad sería de carácter subjetivo. En cambio, tratándose de las obligaciones de resultado, la no obtención del mismo es constitutiva de incumplimiento y daría paso a una responsabilidad que se califica de objetiva, no obstante reconocerse el obstáculo del tenor del artículo 1547 del Código civil. Sobre el particular, véase PizArRo WILsON, Carlos, La culpa como elemento constitutivo del incumplimiento en las obligaciones de medio o de diligencia, en Revista de Derecho Pontificia Universidad Católica de Valparaíso 31 (2008), pp. 255-265. Peñailillo Arévalo, Daniel, Responsabilidad contractual objetiva, en PiZARRo Wilson, Carlos (editor), Estudios de Derecho Civil IV (Santiago, Editorial LegalPublishing, 2009), pp.331-346.

Por nuestra parte, nos parece más coherente con las disposiciones del Código civil en materia de responsabilidad civil separar el plano del cumplimiento e incumplimiento contractual de aquel de atribución de responsabilidad. En el primero es donde creemos cobra relevancia la distinción entre obligaciones de medios y resultado, contribuyendo a precisar el contenido de las obligaciones de las partes y por tanto, permitiendo definir el incumplimiento. Una vez verificado y acreditado éste, que se construye siempre de forma amplia y objetiva, se presume culpable de conformidad al artículo 1547 del Código civil. En esta dirección: Vidal Olivares, Álvaro, Incumplimiento y atribución de responsabilidad en las obligaciones de medio y resultado (a propósito de una sentencia de la Corte Suprema No de ingreso 1771-2007), en Departamento de Derecho Privado Universidad de Concepción (coordinador), Estudios de Derecho Civil V (Santiago, Abeledo Perrot, 2010), pp. 569-585. Asimismo: Brantt, María Graciela, El caso fortuito y su incidencia en el derecho de la responsabilidad civil contractual (Santiago, Abeledo Perrot, 2010) pp. 206 y ss. También Vidal Olivares, Álvaro - BrantT, María Graciela, Cumplimiento e incumplimiento y responsabilidad del deudor en el Código civil. A propósito de la sentencia de la Corte Suprema de 7 de septiembre de 2010, en Revista de Derecho Universidad Católica del Norte 19 (2012) 1, pp. 271-291.

7 Peñailillo, Daniel, cit. (n.1), pp. 223; Jordano Fraga, Francisco, Obligaciones de medios y de resultado. (A propósito de alguna jurisprudencia reciente), en Anuario de Derecho Civil 44 (1991) 1, p. 6.

${ }^{8}$ Afirmando que la mayoría de los contratos de servicios generan obligaciones de 
comentaremos luego, podrán ser de una u otra clase según la naturaleza del servicio convenido, lo que se aprecia especialmente en los contratos de servicios profesionales, a diferencia del contrato de obra que envuelve siempre una obligación de resultado.

Los contratos de servicios y el intercambio que suponen, precio por un hecho o actividad, aparecen relegados a un segundo plano en nuestro Código civil, con un carácter más bien excepcional ${ }^{9}$. Así, si nos situamos en las normas sobre efectos de las obligaciones, a propósito del incumplimiento, solo los artículos 1553 y 1555 se refieren específicamente a las obligaciones de hacer y no hacer. Por su parte, en la regulación particular de los contratos, la noción de servicios fue recogida-siguiendo la tradición roman $\mathrm{a}^{10}$ - en el contrato de arrendamiento, distinguiéndose tres tipos contractuales, posiblemente aplicables: la confección de una obra material, el de arrendamiento de servicios inmateriales y el de arrendamiento de transporte, con escasas normas y con remisiones recíprocas que deben considerarse para definir las disposiciones concretamente aplicables en cada caso. Adicionalmente, se encuentra la regulación del mandato, en la que merece especial atención el artículo 2118, que ordena aplicar sus normas a relaciones contractuales que pueden encasillarse en la idea de servicio, abriendo otro campo de regulación posible.

A partir del escenario descrito cabe afirmar que el contrato de servicios en nuestro derecho es en rigor atípico, en tanto carece de una reglamentación sistemática destinada especialmente a fijar su régimen supletorio. Esto tiene especial relevancia para la construcción de la regla contractual por la que las partes quedan vinculadas y que determina los derechos y obligaciones que han asumido ${ }^{11}$. En dicho proceso debe acudirse, en primer lugar, a la sola declaración de voluntad, a la que debe incorporarse, por vía de interpretación integradora, todos aquellos elementos que forman parte

resultado: Rodríguez, María Sara, Responsabilidad por incumplimiento de contratos de servicios, en RCHD. 42 (2014) 3, p. 797. En la línea de afirmar que sus obligaciones son predominantemente de medios: Villanueva Lupión, Carmen, cit. (n.4), p. 86 y ss.

9 En España destacan un fenómeno similar: Díez-Picazo, Luis, cit. (n. 4), pp. 278-279; Moreno QueSAdA, Bernardo, cit. (n.4), p. 467.

${ }^{10}$ Guzmán Brito, Alejandro, Derecho Privado Romano (Santiago, Editorial Jurídica de Chile), II, pp. 154 y ss. Barros Bourie, Enrique, cit. (n.1), p. 327 y ss; SEVERÍn Fuster, Gonzalo, Los contratos de servicios: su construcción como categoría contractual, y el derecho del cliente al cumplimiento especifico (Tesis doctoral [inédita], Universidad Autónoma de Madrid, 2014), pp. 116-134.

${ }^{11}$ Sobre la tarea destinada a tal definición: VIDAL OlIVARES, Álvaro, La construcción de la regla contractual en el derecho civil de los contratos, en Revista de Derecho Pontificia Universidad Católica de Valparaíso 21 (2000) pp. 209 y ss. 
del ambiente contractual, adquiriendo especial relevancia la buena fe y los usos contractuales, conforme a lo previsto en el artículo 1546 del Código civil. Y en silencio de las partes, ha de recurrirse, por vía de integración, al derecho supletorio, precisamente destinado a llenar las lagunas que hayan quedado en la declaración de voluntad. Esto último es especialmente relevante cuando la declaración de voluntad es escueta o escasa, algo no poco frecuente en general en los contratos.

Para la construcción del régimen supletorio aplicable a los contratos de servicios, como ya se dijo, encontramos una pluralidad de regímenes o normas posiblemente aplicables en algún sentido cuyo alcance es necesario precisar. En este contexto, la doctrina nacional se ha limitado hasta ahora a señalar genéricamente el conjunto de disposiciones aplicables, sin atender ni examinar el contenido de estas reglas, ni fijar tampoco su real alcance y aplicación a los contratos de servicios ${ }^{12}$. Situación similar se aprecia en nuestra jurisprudencia, que suele aludir genéricamente a la aplicación de las reglas del mandato y del contrato de arrendamiento, pero tampoco precisa su alcance, ni resuelve sobre la aplicación concreta de cada norma ${ }^{13}$.

El único contrato de prestación de servicios que ha suscitado mayor interés es el de servicios médicos, en el que se ha intentado avanzar en la construcción de su estatuto, así por ejemplo, Pizarro plantea que estamos

${ }^{12}$ Así, sólo a modo de ejemplo, es recurrente encontrar afirmaciones en el sentido de que su régimen "debe reconstruirse a partir de normas dispersas en el Libro IV del Código Civil chileno, tales como las relativas al contrato de confección de obra (artículos 1996 a 2005), al arrendamiento de servicios inmateriales (artículos 2006 a 2012) y al arrendamiento de transporte (artículos 2013 a 2021). Hay que reconocer también la prestación de unos determinados servicios en el régimen del mandato (Título XXIV del Libro IV) y en el depósito remunerado, que según el artículo 2219 es un arrendamiento de servicios de custodia, artículos todos estos que aportan elementos normativos al contrato". Rodríguez, María Sara, cit. (n. 8) p. 794. En la misma línea Domínguez, Carmen, Naturaleza y fundamento de la responsabilidad civil del profesional liberal, en Anales Derecho UC. Temas de responsabilidad civil 1(2006) p. 123 , sostiene que la responsabilidad de los profesionales liberales se regiría por "los principios que emanan de la aplicación de las reglas del mandato (C.C. art. 2118) y, en lo que no fueren incompatibles con aquellas, por las del arrendamiento de servicios inmateriales (C.C. art. 2012)".

13 Así, solamente a modo de ejemplo también, se pueden citar en dicha línea: Sentencia de la Corte Suprema, 17 de julio de 2010, rol 3642-2010, partes Banco Santander Chile contra Mellado Fontenelle, Fernando, disponible en www. legalpublishing3.cl, identificador CL/JUR/3814/2010, Sentencia de la Corte Suprema, 10 de noviembre de 2011, rol 9162/2010, partes Espacio Público Ltda. con Champion S.A., disponible en www.vlex.com identificador VLEX-333767730; Sentencia de la Corte Suprema, 2 de julio de 2014, rol 6943/2013, partes Amín González con Faúndez Durán, disponible en www.vlex.com identificador VLEX-518183778. 
en presencia de un contrato atípico y complejo: "Atípico en el sentido que no aparece su régimen legal descrito en forma sistemática por el legislador. Complejo, bajo el prisma que confluyen en su contenido un conjunto de obligaciones y derechos, cuyo origen se encuentra en las prácticas, la lex artis y en forma dispersa por la voluntad del legislador ${ }^{14}$ ". En rigor tampoco aclara con precisión el derecho que supletoriamente resulta aplicable ${ }^{15}$.

Las alusiones genéricas que mayoritariamente hace la doctrina a las reglas del mandato y arrendamiento deja sin respuesta adecuada una serie de interrogantes: ¿cuáles de estas normas realmente resultan aplicables?; ¿prima un estatuto por sobre el otro?; ¡es posible aplicar conjuntamente disposiciones pertenecientes a los distintos contratos?; y ¿qué rol cumplen las reglas generales del Libro IV del Código civil?

Todo lo anterior plantea la necesidad de precisar cómo se conjugan las diversas disposiciones de los distintos textos legales, generales o particulares, a efectos de configurar el régimen supletorio aplicable. En esta ocasión, como una forma de avanzar en la materia, nos parece útil acudir al modelo de dos contratos de prestación de servicios, frecuentes en la práctica y que, conforme se aprecia en la jurisprudencia, plantean problemas cuya solución presupone definir en concreto la normativa supletoria aplicable. En particular acudiremos al contrato de prestación de servicios profesionales y al contrato de prestación de servicios de ejecución de una obra material. El interés en estos modelos obedece a que creemos que gran parte de la prestación de servicios, regidos por el Código civil ${ }^{16}$, pueden ser subsumidas en estos contratos.

${ }^{14}$ Pizarro, Carlos, El contrato médico. Calificación, contenido y responsabilidad, en RCHD. 41 (2014) 3, p. 829.

${ }^{15}$ El régimen legal supletorio Pizarro, Carlos, El contrato médico, cit. (n. 14) pp. 829 ss., lo configura teniendo en consideración, como normativa especial, la ley No 20.584 sobre derechos y deberes de los pacientes que imponen ciertos deberes específicos, como el de información o seguridad. Reconoce, además, que el contrato de arrendamiento de servicios es aplicable, mas no aclara su alcance y expresamente excluye la calificación de mandato y la aplicación de sus normas, por resultar impertinentes desde una perspectiva normativa, práctica e histórica..

${ }^{16}$ Queremos prevenir que empleamos la expresión contratos de servicios para referirnos a lo que comúnmente en nuestro derecho se ha llamado contrato de obras porque existe un hacer concernido, que resulta fundamental en la modificación o transformación de la sustancia que da lugar a la obra (resultado), no obstando su materialidad a esta calificación. En definitiva lo propio de un contrato de servicios está presente en esta figura. En esta línea, en los Principles of European Law. Service Contracts o PEL SC, cuerpo que constituye uno de los antecedentes del Marco Común de Referencia, en el contexto de la modernización y uniformación del derecho privado y de contratos europeo, se contemplan expresamente dentro de las modalidades específicas del contrato de servicios, al menos dos que se pueden iden- 
A continuación intentaremos responder las interrogantes formuladas centrándonos en dos aspectos relevantes en todo contrato: los derechos y obligaciones que emanan del mismo y los remedios del acreedor frente al incumplimiento, primero tratándose del contrato de prestación de servicios profesionales y luego, a propósito del contrato de servicios de ejecución de una obra material. Finalizaremos con un cuerpo de conclusiones.

\section{El CONTRATO DE PRESTACIÓN DE SERVICIOS}

\section{PROFESIONALES}

En este primer contrato que analizaremos es donde se advierte con claridad las dificultades derivadas de la pluralidad de normativa aplicable. Para ejemplificar lo descrito nos basaremos en dos contratos de esta clase, cuyas controversias han llegado a nuestros tribunales. En el primero, se contratan los servicios profesionales y de asesoría técnica, con ocasión de las negociaciones llevadas a cabo con una empresa, a raíz de la construcción de una central hidroeléctrica y de la necesidad de esta empresa eléctrica de constituir servidumbre de tránsito sobre los terrenos colindantes. Se fijó como honorarios el 10\% neto de los ingresos que el cliente o sus sucesores obtuviesen a título de indemnización, ya sea como daño emergente, lucro cesante o cualquier otra como consecuencia de la imposición de un gravamen o servidumbre del predio de que son dueños ${ }^{17}$.

En el segundo, las partes celebraron un contrato de prestación de servicios cuyo objeto era efectuar, por parte de los arquitectos contratados, un proyecto de urbanización, loteo y modificación de vialidad pública, el que debía ser presentado a la Dirección de obras de la I. Municipalidad respectiva, con la finalidad de obtener la resolución de aprobación de los mismo. El valor de los servicios se pactó en 3.500 UF, pagadera en dos cuotas iguales, una al presentar el proyecto de loteo y urbanización para su aprobación en la Dirección de obras de la I. Municipalidad respectiva

tificar con el contrato de obra: el de construcción (regulado en el capítulo 2); y el de mantenimiento y reparación de bienes (regulado en el capítulo 3). Dejamos fuera el contrato de arrendamiento de transporte en el entendido de que la mayoría de las veces queda sujeto a las normas del Código de Comercio, y en esta ocasión nos interesa quedarnos con la regulación del Código Civil. Por la misma razón no abordamos la normativa de la Ley 19.496 sobre Protección a los derechos de los consumidores, que en todo caso es bastante escueta en lo que refiere específicamente a los servicios.

17 Sentencia de la Corte Suprema de 10 de febrero de 2015, Rol 10784-2014, partes Jorge Abud Bannen y Compañía Limitada con Rafael Middleton Barahona, disponible en www.legalpublishing3.cl, cita online CL/JUR/715/2015; 85973. 
y, la otra, al momento en que esa autoridad otorgara el permiso de urbanización y loteo ${ }^{18}$.

Si entre las partes se suscitara controversia ${ }^{19}$ con relación al cumplimiento de estos contratos, en concreto: el alcance de los servicios profesionales y la asesoría misma comprometida, en la que está concernida la ejecución de actos materiales y jurídicos, en el primer caso; y, por otro, en el segundo caso, en el contenido mismo y alcance del proyecto de urbanización; resulta claro que la problemática se centra en la necesidad de precisar a qué se ha obligado el prestador del servicio profesional. No es inusual, como ya adelantáramos, que el contrato, como portador de la declaración de la voluntad de las partes, no se baste a sí mismo para establecer con precisión sus derechos y obligaciones y sea necesario proceder a colmar los vacíos o lagunas, cobrando especial relevancia la normativa supletoriamente aplicable para determinar las obligaciones de las partes y los derechos que le asisten en caso de incumplimiento contractual ${ }^{20}$.

En este escenario, en la estructura del Código civil, como se anticipó es posible acudir a las normas del mandato y/o del contrato de arrendamiento de servicios inmateriales como lo ha puesto de relieve la doctrina y la jurisprudencia nacional. Pretendemos dilucidar, como cuestión previa, la posible compatibilidad de las reglas contenidas en el contrato de arrendamiento de servicios inmateriales y del mandato, para luego establecer si estas disposiciones efectivamente precisan las obligaciones que las partes han asumido y los remedios de que el acreedor goza frente al incumplimiento.

\section{Coordinación de las reglas del contrato de mandato y de arrendamiento} de servicios inmateriales

Ante la existencia de estos dos grupos de normas es posible preguntarse ¿cuándo se aplican las reglas del contrato de mandato y cuándo las del arrendamiento a los servicios profesionales? ¿Son normas compatibles o incompatibles?

Si nos remitimos a la regulación del contrato de mandato, el artículo 2118 dispone: "los servicios de las profesiones y carreras que suponen largos estudios, o a que está unida la facultad de representar y obligar a otra persona respecto de terceros, se sujetan a las reglas del mandato".

18 Sentencia de la Corte Suprema de 28 de diciembre de 2012, Rol 9468-2010, partes Edmundo Latino Bouillet con Inmobiliaria Santa Gloria Limitada, disponible en www.vlex.com, identificador: VLEX-436702014.

${ }^{19}$ En estos casos en rigor la controversia no se centró en el contenido de la obligación que asumió el prestador del servicio, mas nos sirven para ilustrar la problemática a que pueden dar lugar con ocasión de la obligación de hacer que surge de ellos.

${ }^{20}$ En tal sentido: Vidal Olivares, Álvaro, cit. (n. 11) pp. 209 y ss. 
Lo primero que debe consignarse es que, en rigor, esta disposición no califica a los servicios de estos profesionales como mandato, sino que precisa que se sujetan a sus reglas en los dos casos que prevé: servicios de profesionales cuyas carreras suponen largos estudios, donde entendemos pueden quedar comprendidos gran parte o todos estos servicios-médicos, abogados, arquitectos, contadores, ingenieros, etc.- y aquellos en que va unida la facultad de representar. Lo anterior es relevante porque parte de la doctrina ha excluido la aplicación de los preceptos del mandato, no obstante el tenor del artículo 2118, porque el objeto del contrato de prestación de servicios no coincidiría con el objeto propio del mandato, en tanto el profesional no ejecuta uno o más negocios por cuenta y riesgo de otra persona ${ }^{21}$.

Es relevante dejar establecido que no obstante la amplitud de la remisión lo cierto es que sólo resultan aplicables aquellas disposiciones compatibles con la naturaleza de los servicios profesionales y que no correspondan a particularidades de la naturaleza del mandato. Así lo destaca Barros ${ }^{22}$, señalado que aquellas normas del mandato "que se refieren a cuestiones típicas de la gestión de negocios ajenos no serán per se aplicables a otros contratos de servicios"; y que en cambio hay otras que son aplicables analógicamente.

A partir de lo explicado precedentemente creemos carece de importancia acudir a perfilar el objeto del mandato y del arrendamiento de servicios inmateriales como criterio para determinar la normativa aplicable. Además, desde una perspectiva práctica, los servicios que prestan los profesionales presuponen carreras de largos estudios lo que conllevará a la aplicación necesaria de las reglas del mandato ${ }^{23}$.

${ }^{21}$ Pizarro Wilson, Carlos, cit. (n. 14) pp.827-830; Mantilla, Fabricio, El contrato de prestación de servicios médicos en el derecho colombiano, en GUZMÁN BRITO, Alejandro (editor), Colección de estudios de derecho civil en homenaje a la profesora Inés Pardo de Carvallo (Valparaíso, Editorial Universitaria de Valparaíso, 2008), pp. 585-588.

${ }^{22}$ Barros Bourie, Enrique, cit (n.1) p. 331.

${ }^{23}$ Tratándose del objeto del contrato de mandato la doctrina ha puesto de relieve su vinculación con los actos jurídicos indicándose esto como lo propio. Las principales razones que se esgrimen son: 1) El contrato de arrendamiento de servicios es el estatuto general en nuestro derecho al comprender todas las prestaciones de servicios, con excepción de las que se refieran al mandato u otros contratos específicos. 2) En la estructura del mandato se presume la representación y esta sólo procede tratándose de actos jurídicos. 3) Todos los ejemplos que en esta clase de contrato de arrendamiento proporciona el legislador se refiere a hechos materiales y no jurídicos. Así lo recoge Stitchkin, autorizada voz en la materia, quien agrega al objeto del mandato la administración de negocios de índole económica que sean materia de una ocupación lucrativa o de interés. Cfr. Stitchkin Branover, David, El mandato civil (5ª edición, Santiago, Editorial Jurídica de Chile, 2008), pp. 41-46. 
Si nos situamos en el contrato de arrendamiento, el artículo 1915 del Código civil al definirlo dispone "es un contrato en que las dos partes se obligan recíprocamente, la una a conceder el goce de la cosa, o a ejecutar una obra o prestar un servicio, y la otra a pagar por este goce, obra o servicio un precio determinado". De las tres clases de arrendamiento que se desprenden de la referida norma, como adelantáramos, interesa el contrato de arrendamiento de servicios inmateriales, regulado en el párrafo $9^{\circ}$, artículos 2006 a 2012 del Código civil.

A partir de lo dispuesto por los artículos 1915 y 2006 puede entenderse que el arrendamiento de servicios inmateriales es un contrato en que las dos partes se obligan recíprocamente, la una a ejecutar una obra inmaterial, o en que predomina la inteligencia sobre la mano de obra, como una composición literaria o la corrección tipográfica de un impreso, y la otra a pagar por este servicio un precio determinado ${ }^{24}$. De conformidad a estas disposiciones y teniendo en consideración además los artículos 2007 y 2012, los autores han hecho presente que el Código civil distingue a su vez tres clases de contrato de arrendamiento de servicios inmateriales: a) aquel en que predomina la inteligencia por sobre la obra de mano; b) aquel que consiste en una larga serie de actos y c) servicios prestados por profesionales ${ }^{25}$.

Conviene precisar que la prestación de servicios profesionales, objeto del contrato de arrendamiento, debe hacerse de forma independiente, ya que de lo contrario quedaría subsumida en la regulación del contrato de trabajo, regido por la legislación laboral ${ }^{26}$.

Tratándose de los servicios prestados por profesionales la representación es uno de los elementos que usualmente se emplea para diferenciarlo con el mandato. Sin embargo, en realidad, se alude al negocio encomendado y a la forma de actuación del mandatario: por cuenta y riesgo del mandante $^{27}$. En efecto, la doctrina ha insistido en diferenciarlo con el mandato precisamente porque en éste la gestión de uno o más negocios se efectúa por cuenta y riesgo del mandante, mientras que en el contrato de arrendamiento de servicios inmateriales el objeto del contrato consiste en la actividad intelectual del arrendador que se materializa en la confección de

${ }^{24}$ En el mismo sentido Stitchrin Branover, David, cit. (n. 23) p. 73.

${ }^{25}$ Cfr. Meza Barros, Ramón, Manual de Derecho civil, de las fuentes de las obligaciones (9a edición, Santiago, Editorial Jurídica de Chile, 2010) I, pp. 127-128.

${ }^{26}$ Rodríguez Guitián, Alma, El desistimiento en el contrato de servicios de los profesionales liberales, en Anuario de Derecho civil 54 (2001) 2, p.682. STITCHKIN Branover, David, cit. (n. 23), p. 74.

${ }^{27}$ Cfr. Stitchkin Branover, David, cit. (n. 23), pp.41-46. 
la obra en que predomina la inteligencia ${ }^{28}$. Nosotros entendemos, como ya lo adelantáramos, que lo referido al objeto no resulta determinante porque el artículo 2118 no identifica los servicios profesionales con el mandato. Por otra parte, la representación, elemento de la naturaleza del contrato de mandato y diferente de la forma en que actúa el mandatario, tampoco es relevante, porque la referida disposición sujeta a las reglas del mandato indistintamente a las profesiones que involucran o no representación.

Habiéndose afirmado la aplicación de las reglas del mandato a los servicios profesionales, queda por precisar si estas disposiciones pueden o no aplicarse conjuntamente con las del contrato de arrendamiento de servicios inmateriales o si una de ellas prevalece por sobre la otra ${ }^{29}$. La respuesta la proporciona el tenor del artículo 2012, que hace aplicable a los supuestos contemplados en el artículo 2118 las reglas del contrato arrendamiento de servicios inmateriales, en lo que no tuvieren de contrario a ellas.

La revisión de estas disposiciones, como lo veremos a continuación, demuestra que realmente no existe incompatibilidad entre estas normativas que conlleve a que primen las normas del mandato por sobre las del arrendamiento, excluyéndolas. Esto nos permite afirmar su aplicación conjunta a los servicios profesionales, de manera que la normativa general supletoria para estos está conformada por el conjunto de estas disposiciones.

Precisado lo anterior, resta dilucidar si el conjunto de estas reglas fija los derechos y obligaciones de las partes y remedios frente al incumplimiento, que es lo que analizaremos en el apartado siguiente.

2. Contenido de las obligaciones de las partes y remedios frente al incumplimiento contractual

Las obligaciones que nacen de este contrato, como sabemos, son la realización del servicio comprometido y pagar el precio por este. En lo sucesivo revisaremos las normas pertinentes, comenzado con las reglas del contrato de arrendamiento para concluir con las del mandato, sin perjuicio de revisarlas conjuntamente tratándose de la obligación de pagar el precio, por la razón que a continuación explicaremos.

Con relación a la obligación de pagar el precio o la remuneración, es el único caso en que advertimos una aparente falta de coincidencia entre las reglas del mandato y el arrendamiento de servicios, ya que el artículo 1997, a propósito del contrato de arrendamiento para la confección de una obra

${ }^{28}$ Cfr. Stitchkin Branover, David, cit. (n. 23), p.74. A propósito de los servicios médicos, Mantilla, Fabricio, cit. (n. 21), pp.485-486; Pizarro Wilson, Carlos, cit. (n. 14), pp. 828-829.

${ }^{29}$ Cfr. Stitchkin Branover, David, cit. (n. 23), pp.74-77. Meza Barros, cit. (n. 25), p. 128. 
material -aplicable por el reenvío que hace el artículo 2006- establece reglas para fijar el precio cuando no se ha convenido: el que ordinariamente se paga y, a falta de éste, el que se estime equitativo por peritos. Se trata de una regla que resulta llamativa desde que, como expresa Meza Barros ${ }^{30}$, la ley se aparta de las generales en la materia, conforme a las cuales no hay arrendamiento ni compraventa si las partes no han convenido en el precio o al menos señalado las normas para determinarlo y aquí, sin embargo, admite que ello haya ocurrido, dictando un precepto destinado a salvar dicha omisión.

Por su parte, la regulación del mandato -artículo 2117- establece otro orden para su determinación supletoria: la ley, la costumbre y el juez ${ }^{31}$.

En la práctica, nos parece, no existe una real falta de coincidencia, en caso de existir controversia, el precio será determinado en definitiva por el juez, según lo que ordinariamente se paga, aplicando en los hechos la misma regla ${ }^{32}$. Además la discusión en torno a la remuneración tiene una incidencia menor porque es usual que las partes la dejen claramente establecida, como queda reflejado en los dos casos descritos previamente; el verdadero conflicto se suscita al momento de determinar el contenido y alcance del servicio profesional comprometido.

Si nos centramos en el contenido de la prestación de hacer-de ejecutar el servicio profesional-, la regulación del contrato de arrendamiento de servicios inmateriales carece de norma que se refiera directamente a ella. No hay realmente una normativa supletoria que permita configurar el contenido de las prestaciones de las partes, aspecto de gran relevancia para poder determinar si se ha verificado o no el cumplimiento por parte del deudor, cuestión que se conecta con la clasificación de obligaciones de medio o de resultado, pues en esta materia -como adelantáramos- es donde pueden generarse dudas con relación al alcance de la prestación

${ }^{30}$ Meza Barros, Ramón, cit. (n. 25) p. 124.

${ }^{31}$ La otra norma que se aplica en la determinación del precio es el artículo 1998 que no supone contradicción con las reglas del mandato ya que se refiere a un tercero a quien se le da la facultad de fijar el precio y muere; si es antes del inicio de la obra el contrato es nulo; si es después este debe ser fijado por peritos.

${ }^{32}$ Ciertamente la regulación del mandato prevé que a falta de lo que pueda establecer la ley se aplican la costumbre, pero en rigor no existe una diferencia con las reglas del contrato de arrendamiento porque se ha entendido por la doctrina nacional que la referencia es al precio que usual u ordinariamente se paga por el servicio. Cfr. Stitchkin Branover, David, cit. (n. 23), pp. 76, 423. En similar dirección y a propósito de la regla prevista para el contrato de arrendamiento -artículo 1997Meza Barros afirma que la fijación pericial del precio requiera que las partes no lo hayan convenido y no sea posible recurrir a normas consuetudinarias que sirvan para determinarlo, Meza Barros, Ramón, cit. (n. 25) p. 124. 
debida. En definitiva, tratándose de la prestación que realmente puede suscitar controversia estas disposiciones nada aclaran.

Si nos situamos ahora en los remedios frente al incumplimiento encontramos algunos preceptos que pueden, en principio, resultar aplicables. Estas son:

Los artículos 2009 y 1999 inciso segundo. Estas disposiciones se vinculan con la terminación del contrato. La primera de ellas faculta a cualquier parte a poner término al servicio cuando quiera o con el desahucio que se hubiere estipulado. Esta norma está prevista para aquellos servicios inmateriales que consisten en una larga serie de actos.

Por su parte, el artículo 1999 inciso segundo faculta al que encargó la obra para hacerla cesar, reembolsando al artífice todos los costos y dándole lo que valga el trabajo hecho y lo que hubiere podido ganar en la obra. Es importante tener presente el contexto de este inciso porque conforme a lo previsto en el anterior se presupone el incumplimiento contractual y el reconocimiento de la indemnización de perjuicios como remedio del acreedor ante este.

Ambas disposiciones facultan para poner término unilateralmente al contrato, sin embargo, difieren porque en el primer caso el ejercicio de esa facultad no trae consecuencias ulteriores para el contratante que la ejerce; mientras que en el segundo, impone la obligación de indemnizar todo perjuicio que sufra el deudor y, desde esta perspectiva, se trata de una solución que se asimila a alguna de las presentes en la normativa jurídica europea ${ }^{33}$.

33 Entre nosotros el desistimiento unilateral o renuncia es vista como una forma de extinción del contrato que consiste "en la facultad concedida por la ley o por la convención a una o más partes para romper unilateralmente el contrato, por su sola voluntad, sin necesidad de incumplimiento de la contraria, bastando su ejercicio de buena fe y noticiarla con un preaviso razonable a la contraria, so pena de indemnizar los perjuicios en caso de ejercicio irregular". Caprile Biernmann, Bruno, El desistimiento unilateral o renuncia: una especial forma de extinción de los contratos, en FigueroA, Gonzalo et al. (editores), Estudios de Derecho civil VI (Santiago, Abeledo Perrot, 2011), p. 271. Tratándose de los servicios profesionales la doctrina ha discutido si el cliente puede desistirse ad nutum, es decir, sin alegar una causa que motive su decisión de colocar término de forma anticipada al contrato. La tendencia en la doctrina ha sido que el ejercicio de esta facultad debe ampararse en una justa causa sólo en caso del prestador del servicio, más tratándose del cliente goza este de libertad al respecto, por considerarse que usualmente la prestación del servicio no es fungible y por la fiducia propia de estos contratos. En todo caso se tiende a dejar indemne a la parte contra quien se ejerce el desistimiento y se exige la necesidad de un aviso previo. Cfr. Rodríguez Guitián, Alma, cit. (n.), pp. 706-734; Villanueva Lupión, Carmen, cit. (n. 4) pp. 146-177. En la normativa jurídica europea el Marco Común de Referencia (DCFR) en su artículo 2:111 reconoce al cliente el derecho a poner término al contrato, bastando solo un aviso previo. Sin embargo, la justificación de 
Nos parece complejo y riesgoso reconocer, como lo hace el artículo 2009 , en todo caso la posibilidad de poner término al contrato de prestación de servicios profesionales simplemente por decisión unilateral de las partes sin consecuencia alguna. En muchas ocasiones el profesional, prestador del servicio, ha incurrido en gastos con ocasión del mismo (inversiones de mayor envergadura) y/o sufre perjuicios por el término anticipado del contrato, siendo razonable para evitar un enriquecimiento sin causa reconocerle el derecho a la indemnización de todo el daño que sufra como consecuencia de él.

No debe perderse de vista que esta alternativa, que puede parecer más idónea para estos contratos, no es en rigor la que prevé el artículo 1999, esta disposición presupone una causa para poner término al contrato: que se haya verificado un incumplimiento por parte del prestador del servicio; $y$, desde esa perspectiva, puede entenderse que la ratio de la norma no difiere radicalmente de la normativa general en la materia, el artículo 1489 del Código civil, siendo necesario un incumplimiento de gravedad para que la terminación -resolución- del contrato pueda prosperar. En la configuración de esta gravedad entendemos es de especial utilidad el criterio de pérdida de confianza; ciertamente el incumplimiento contractual es un hecho amplio y objetivo, mas la conducta que el deudor ha desplegado en su intento de ejecutar la prestación o desplegará, tiene incidencia en la materia, si conlleva a una pérdida de confianza del acreedor, de que el deudor ejecutará la prestación en los términos en que fue convenida, el fundamento directo de la gravedad del incumplimiento así determinado descansa en el tenor del artículo 1546 del Código civil ${ }^{34}$.

esta decisión incide en el reconocimiento del derecho a la indemnización por parte del prestador del servicio. En los Principios de Derecho Europeo sobre contratos de servicios (PEL SC), se reconoce en su artículo 1:115 el derecho del cliente de poner término en cualquier momento el contrato, debiendo sí indemnizar al prestador del servicio, lo que incluye tanto las pérdidas como las ganancias que dejó de percibir. Se persigue dejarlo en la misma posición que si el contrato se hubiese cumplido en tiempo y forma. Tal como lo colocan de manifiesto los comentarios a estos principios, la cancelación es distinta de la terminación porque no se basa en el incumplimiento contractual -esta siempre es posible conforme a las reglas generales- sino que es una facultad del cliente que se produce con total independencia, aun cuando el prestador del servicio lo esté ejecutando bien; es por esto que no se califica como un remedio frente al incumplimiento contractual. BARENDRECHT, Maurits; JANSEN, Chris; LoOS, Marco; Pinna, Andrea, CasçaO, Rui; Van Gulju, Stéphanie, Principles of European Law-Service Contracts (PEL SC) (Munich, Sellier European Law Publishers, 2007), pp. 300-301.

${ }^{34}$ Acerca de la configuración de la gravedad del incumplimiento por pérdida de confianza, como presupuesto de la resolución del contrato, véase Mejías Alonzo, 
Por otro lado, continuando con las disposiciones referidas a los remedios, debemos tener en consideración ciertas reglas previstas en el contrato de arrendamiento para la confección de una obra material, atendido el reenvío que hace el artículo 2006 del Código civil:

El ya aludido artículo 1999 inciso primero reconoce el derecho a solicitar la indemnización de perjuicios conforme a las reglas generales de los contratos, siempre que las partes no hayan ejecutado lo convenido o se haya retardado la ejecución, lo que nos recuerda claramente el contenido del artículo 1556 del Código civil. Y como se trata de una remisión amplia a las reglas generales, entran en ese llamado también el artículo 1547, que habrá de aplicarse para resolver sobre la procedencia de la indemnización y también el artículo 1553 especialmente previsto para regular los efectos del incumplimiento de las obligaciones de hacer; y los artículos 1557 y 1558 acerca de la constitución en mora del deudor como requisitos de la indemnización de perjuicios y acerca de la extensión del daño indemnizable, respectivamente. En definitiva sólo existe una conducción a las reglas generales.

Por su parte, el artículo 2002 entrega a peritos decidir que la obra se ejecutó correctamente en caso de controversia. Y si es fundada la alegación el deudor puede ser obligado a hacerlo de nuevo o a la indemnización de perjuicios. Esta norma aporta en lo referido a la modalidad que puede adoptar la pretensión de cumplimiento, en caso de obligaciones de hacer, sobre lo que volveremos más adelante a propósito del contrato de arrendamiento de obra material.

El resto de las disposiciones contenidas en este párrafo no consigan aspectos relevantes en la materia ${ }^{35}$.

La revisión del conjunto de normas concernidas en esta clase de contrato de arrendamiento, a propósito de los derechos y obligaciones que las partes del contrato asumen, son escasas y de poca utilidad, algo similar ocurre tratándose de los efectos ante el incumplimiento porque la mayoría de ellas coinciden con las reglas generales contenidas en el Libro IV del Código civil, sin que se trate realmente de reglas que permitan hacerse cargo de las particularidades de los contratos de servicios.

Nos centraremos ahora en las reglas del mandato. Para intentar dilucidar la interrogante formulada, tratándose del contenido de la prestación, son normas relevantes:

Claudia, El incumplimiento resolutorio (Santiago, Abeledo Perrot, 2011), pp. 264279.

${ }^{35} \mathrm{El}$ artículo 2010 prevé quién debe abonar los gastos si el prestador del servicio debe mudar de residencia. El artículo 2011 priva de la posibilidad de reclamar gastos de viaje y de desahucio en ciertos casos. 
El artículo 2134, que sujeta la recta ejecución del mandato a la sustancia del negocio encomendado y los medios que designe el mandante, sin perjuicio de que puedan emplearse medios equivalentes si resulta necesario y es posible obtener completamente el objeto del mandato. Esta disposición puede ser de utilidad para efectos de ensanchar el contenido de la prestación, teniéndose en cuenta el negocio encomendado, mas no debe perderse de vista que usualmente los medios que se empleen para la ejecución de la prestación los definirá de mejor manera el prestador del servicio en cuanto especialista de la prestación que ejecuta.

El artículo 2155 obliga al mandatario a dar cuenta de su gestión. La rendición de cuentas será de utilidad para efectos de determinar si se ha verificado o no el cumplimiento del contrato.

Nos parece que el contenido de ambas disposiciones queda subsumido en la estructura general del Código civil, integrándose al contenido de la prestación a partir del tenor del artículo 1546.

Por otra parte, el artículo 2135 establece como elemento de la naturaleza la delegación del encargo. Esta regla nos parece puede ser complicada dependiendo del tipo de contrato de prestación de servicios. Si la prestación del servicio profesional corresponde a aquellos que en doctrina se califican como intuito personae, estaríamos en presencia de una regla que se opone a la estructura de estos contratos, a diferencia de lo que acontecería en otra clase de servicios. Por lo mismo, parece que no puede ser una regla general sino que habrá que distinguirse caso a caso, conforme a la naturaleza de los servicios, tal como lo ha desprendido la doctrina nacional al interpretar la normativa general en la materia.

Con relación a los remedios frente el incumplimiento son relevantes las siguientes normas:

El artículo 2129 precisa que el mandatario responde hasta de culpa leve, norma en principio relevante, para determinar la procedencia de la indemnización de perjuicios. Sin embargo, se trata de una regla que en estricto sentido, para efectos del contrato de servicios, no sería necesaria teniendo en consideración la regla general contenida en el artículo 1547 para toda clase de contrato oneroso ${ }^{36}$.

${ }^{36}$ La norma referida dispone que el mandatario responde hasta de la culpa leve en el cumplimiento de su encargo. La doctrina entiende que es una regla general aplicable con independencia de que el mandato sea o no remunerado y de ahí su particularidad en relación con el artículo 1547 del Código civil. Siempre se responde por culpa leve, la mayor o menor estrictez a la que alude la norma dice relación con la extensión de la indemnización de perjuicios. Cfr. Claro Solar, Luis, Ligeras observaciones sobre la prestación de la culpa en el contrato de mandato, en Revista de Derecho y Jurisprudencia y Ciencias Sociales 7 (1910), pp. 257 y ss. Cfr STITCHKIN BranOvER, 
El artículo 2150 inciso final dispone que el mandatario que se encuentra imposibilitado de cumplir las órdenes del mandante es a quien le compete la prueba del caso fortuito. Esta regla no difiere de la general contenida en el artículo 1547 que impone la misma carga probatoria.

En los artículos 2158 inciso final ${ }^{37}$ y 2159 encontramos referencia a dos remedios sinalagmáticos: la excepción de contrato no cumplido, en ambos y la facultad resolutoria, en la segunda disposición, normas que en estricto sentido reiteran las reglas generales del Código civil contenidas en los artículos 1489 y 1552.

El artículo 2163 prevé que el contrato termina unilateralmente por la renuncia del mandatario y revocación del mandante. Tratándose de la primera, el contenido del artículo 2167 del Código civil nos parece coherente con el modelo que debe primar en los contratos de servicios y que es coincidente con lo ya comentado a propósito del desistimiento unilateral; la renuncia siempre puede ejercerse pero se deja indemne al mandante hasta que pueda proveer a los negocios encomendados.

Luego de la revisión de las reglas del mandato y su análisis creemos que el conjunto de estas disposiciones no contiene realmente norma especial que contribuya eficazmente en la construcción de un régimen supletorio para esta clase de contrato. A la misma conclusión arribamos a partir de las reglas del contrato de arrendamiento, nos parece que todas las disposiciones concernidas reiteran o nos reconducen a las reglas generales contenidas en el Libro IV del CC.

David, cit. (n. 23), pp. 387-388. Por nuestra parte, creemos que es intrascendente esta diferencia en los contratos de prestación de servicios que por su estructura son onerosos. Por otro lado, tratándose del mandato, nos parece más acorde a las reglas de la responsabilidad civil contractual situar la culpa en la determinación de su procedencia y no en la extensión del daño indemnizable; la estrictez dice relación con la construcción del modelo de diligencia.

${ }^{37} \mathrm{La}$ disposición establece que el mandante no puede dispensarse de cumplir sus obligaciones alegando que el negocio encomendado no tuvo éxito o que pudo desempeñarse a menor costo, salvo que pruebe la culpa del mandatario. En la terminología que emplea el legislador se confirma que la obligación que asume el mandatario es de medios, y que lo que contempla a favor del mandante es una excepción de contrato no cumplido: la prueba de la culpa a la que alude el legislador es equivalente a la prueba del incumplimiento, y solamente si lo acredita puede dejar de cumplir sus propias obligaciones. Sobre el particular y en tal sentido: VIDAL OlIVARES, Álvaro; BrantT, María Graciela, Obligación, incumplimiento y responsabilidad civil del mandatario en el Código Civil chileno, en RCHD. 40 (2013) 2, pp. 413-431. 


\section{Contrato DE SERVICIOS DE EJECUCIÓN DE UNA OBRA}

MATERIAL

Otro de los contratos de más frecuente celebración práctica es el de servicios de ejecución de una obra material: aquel en que una de las partes encarga a la otra la realización -a partir de una cierta materia o sustancia-de una obra material determinada, una opus nueva, a cambio de una suma de dinero. Este contrato genera una obligación de hacer-elaborar la obra de que se trate y entregarla o ponerla a disposición de quien la encargó- que se identifica con la idea de servicio ya referida ${ }^{38}$.

Puede servir para ilustrar la aplicación de este contrato en la práctica y las interrogantes que surgen respecto de la configuración concreta del régimen jurídico supletorio aplicable, los hechos de dos casos fallados por nuestros tribunales:

El primero de ellos, corresponde a un contrato denominado por las partes como "contrato de administración", por el cual se encargó, a cambio de una suma de dinero convenida, la ejecución de un proyecto de rehabilitación de un antiguo inmueble de Valparaíso, según planos presentados a la Municipalidad respectiva. El contrato comprendía las obras destinadas a habilitar algunos departamentos, y se extendía también a la administración técnica y financiera de la ejecución del mencionado proyecto. Se acordó asimismo que formaban parte del contrato, los planos y especificaciones técnicas, confeccionados por un arquitecto debidamente individualizado. La parte que encargó la obra, luego de concluidos los trabajos, demanda el cumplimiento del contrato y la indemnización de los perjuicios, fundada

${ }^{38}$ Como expresa Orrego, refiriéndose al contrato para la confección de una obra material, en estos casos "el arrendador pone su trabajo o experticia al servicio de otro, con el fin de transformar una materia y confeccionar una nueva obra para el arrendatario". ORREGo, Juan Andrés, El contrato de arrendamiento (Santiago, Editorial Metropolitana, 2011) p. 455. Cabe hacer presente al respecto que en el derecho español tradicionalmente se ha realizado una distinción entre lo que se entiende como contratos de servicios y los contratos de obra, básicamente a partir de la existencia en estos últimos y, ausencia en los primeros, de un producto resultante de la actividad del deudor, a diferencia de lo que acontece en los contratos de servicios, en que lo debido es únicamente la referida actividad. Así lo destaca VilLANUEVA LUPIÓn, Carmen, cit. (n. 4) pp. 86 y ss. Por nuestra parte, creemos que tal distinción carece de sentido si se caracteriza a los servicios como un hacer que se realiza a favor de otro, y entendemos que puede o no traducirse en la concreción de una obra como un producto resultante de ese hacer. La existencia de dicho producto incidirá en la calificación de la obligación correspondiente como de resultado, pero no impedirá calificar al contrato como uno de servicios. De ahí que ubiquemos el contrato de obra como uno de servicios. 
en que la obra no se ejecutó en la forma pactada, presentando una serie de deficiencias. Por su parte, el demandado, junto con negar el incumplimiento, argumentando que la obra fue debidamente recepcionada por la Municipalidad, deduce demanda reconvencional fundado en la existencia de gastos no incluidos en el contrato, derivados de mayores obras y otras labores ejecutadas ${ }^{39}$.

En un segundo caso, se celebra un contrato por el cual una de las partes se obliga para con la otra a la construcción de una casa y un galpón en un terreno de propiedad de esta última, acordándose un plazo para la ejecución y un precio único por toda la obra. La celebración fue consensual, sin que se incorporara al contrato ningún proyecto, planos ni especificaciones técnicas que fijaran las características de la obra contratada. Luego de realizados los trabajos, la parte que los había encargado ejerce una acción de cumplimiento de contrato e indemnización de perjuicios en contra del constructor, fundada en el retraso en la entrega y en la existencia de diversos defectos de construcción. El demandado niega el retraso y por el contrario, afirma que cumplió íntegra y oportunamente y que la demandante recibió conforme las obras ${ }^{40}$.

En ambos supuestos el conflicto entre las partes del contrato dice relación con el (in)cumplimiento de las obligaciones contraídas por el obligado a la ejecución de la obra. Tal discusión, como quedó de manifiesto, a propósito del contrato de servicios profesionales, corresponde precisamente a uno de los principales problemas a que dan lugar en general los contratos de servicios y se presenta muy frecuentemente en aquellos cuyo objeto es la ejecución de una obra material, como sucede por ejemplo, en el terreno de la construcción. Y la solución de tal conflicto presupone definir el contenido y alcance de las obligaciones contraídas por las partes $y$, fundamentalmente, de aquella consistente en la realización de la obra concernida en cada caso. Sólo si existe claridad sobre aquello, a lo que se obligó el deudor, es posible establecer si ha infringido o no la obligación. $\mathrm{Y}$, como también ya adelantamos, el otro aspecto que suele ser fuente de dificultades y que se conecta con el anterior, es el de los mecanismos de

39 El caso fue fallado por sentencia de la Corte de Apelaciones de Valparaíso de 10 de diciembre de 2012, rol 1595-2012, partes Sangueza con Espinoza, disponible en www.vlex.com identificador VLEX-412702890, confirmada por sentencia de la Corte Suprema de 13 de mayo de 2013, rol 323-2013, disponible en www.vlex.com identificador VLEX-438375754.

${ }^{40}$ El caso fue resuelto en casación por sentencia de la Corte Suprema de 29 de mayo de 2014, rol 2073-2013, partes Inversiones Clarkson y Compañía Limitada con Donoso, disponible en www.legapublishing3.cl identificador CL/JUR/2748/2014. 
protección de que dispone el acreedor de la obligación de hacer en esta clase de contratos.

En los casos referidos resulta patente la insuficiencia de la declaración de voluntad de las partes para resolver las interrogantes formuladas, especialmente en el segundo atendida la ausencia de especificaciones técnicas previstas, cobrando relevancia-como ya se ha dicho-el derecho supletorio aplicable.

Como hemos adelantado, respecto de esta cuestión nuestro Código civil nos conduce inevitablemente al contrato de arrendamiento. En efecto, el artículo 1915, al definir dicho contrato, establece que, entre otros objetos, en él las partes se pueden obligar recíprocamente a ejecutar una obra y a pagar por ella un precio determinado. A la primera se la denomina arrendador o artífice y a la segunda, arrendatario. Luego, dentro de dicho título se ubica el párrafo 8, que el legislador denomina "De los contratos para la confección de una obra material", en el que se contienen diez artículos, entre el 1996 y el 2005, algunos de los cuales son aplicables a los contratos de prestación de servicios profesionales como ya se mencionó. Por consiguiente, podemos decir que estas normas constituyen la regulación especial que dentro del Código civil resultaría aplicable a los contratos de servicios cuyo objeto es la ejecución de una obra material, en aquellos casos en que tales contratos queden dentro de la órbita del arrendamiento ${ }^{41}$. Asimismo, hay que precisar que el artículo 2003, ubicado dentro del párrafo mencionado, está destinado a aplicarse específicamente a los contratos para la construcción de edificios en que un empresario se encarga de toda la obra por un precio único prefijado -los llamados contratos de construcción a suma alzada, que constituyen una modalidad especial de esta forma de arrendamiento- que, por tanto, quedan regidos por esta regla de manera preferente, además de las restantes del párrafo.

La cuestión a dilucidar es si aquí encontramos respuesta a las dos interrogantes planteadas inicialmente tratándose de esta clase de contratos. La

${ }^{41}$ Es preciso recordar que conforme a lo previsto en el artículo 1996, los contratos en que se encarga la confección de una obra material son calificados de venta o de arrendamiento según quien aporte la materia, al menos la principal, para la confección de la obra. Conforme a dicho criterio, quedan sujetos a las reglas del arrendamiento -y por tanto entran en lo que hemos denominado contrato de servicios- aquellos en que dicha materia ha sido suministrada por quien ha encargado la obra. Sobre las dificultades que se presentan con ocasión de la delimitación: SAN MARTín, Lilian, Algunas consideraciones sobre el contrato para la confección de obra material. Problemas derivados de su configuración típica, en VIDAL, Álvaro et al, Estudios de Derecho Civil X (Santiago, Thomson Reuters, 2015), pp. 753 y ss. 
revisión de las normas en cuestión arroja los siguientes resultados, respecto de las obligaciones de las partes:

Tratándose del pago del precio, a ella se destinan únicamente los artículos 1997 y 1998, ambos examinados a propósito de los contratos de servicios profesionales y que, como ya señalamos, son de dudosa utilidad práctica porque en estos contratos suele fijarse de manera precisa el precio.

Adicionalmente, hay que considerar que dentro de la regulación especial del contrato a suma alzada del artículo 2003, las reglas primera y segunda se refieren a la obligación de pagar el precio y más concretamente, a un conflicto que sí suele presentarse en contratos de este tipo: lo referido a posibles aumentos de precio, por mayores costos o modificaciones en la obra. En ellas se regula tal cuestión, siendo, sin embargo, bastante restrictivo el legislador a la hora de autorizar dichos incrementos. Tratándose de aumentos en el precio de jornales o materiales, conforme a la regla primera solamente se permiten los aumentos de precio en caso de haberse ajustado un precio particular por las agregaciones o modificaciones. Y si se trata de aumentos de costos por circunstancias desconocidas, según lo dispuesto por la regla segunda, el empresario debe obtener autorización del dueño. De negarse éste, podrá recurrir al juez para que resuelva sobre la procedencia del aumento de precio, y lo fije, de ser necesario. Esta última regla suele ser destacada por tratarse de una de las escasas normas que en nuestro derecho admite la revisión judicial del contrato, en caso de producirse un cambio de circunstancias de aquellos que dan lugar a la denominada doctrina de la imprevisión ${ }^{42}$.

De esta forma, se puede observar que la regulación respecto de la obligación de pagar el precio es bastante escasa, lo que, sin embargo, no parece negativo, atendida la menor complejidad que ella presenta dentro del contrato; y que aquello que sí suele dar lugar a dificultades, es considerado por el legislador.

Por su parte, tratándose de la obligación de ejecutar la obra, lo primero que se advierte es que en el párrafo examinado no hay normas que se refieran

${ }^{42}$ Así lo afirma López Santa María, Jorge, Los contratos. Parte general (Santiago, Abeledo Perrot, 2010), p. 251. De hecho, en el primero de los casos antes expuestos, el encargado de la ejecución de la obra dedujo demanda reconvencional argumentando la realización de nuevas obras y mayores costos de las pactadas. Sin embargo, el tribunal de primera y segunda instancia rechazan la acción, fundados en la regla primera del artículo 2003, precisamente por no existir un precio particular fijado por las partes por esas supuestas obras extras. Y la Corte de Apelaciones agrega que la regla segunda de la misma disposición contempla una acción diversa si se trata de costos no previstos por circunstancias desconocidas. Esa acción diversa aludida por la Corte corresponde a la que permite la revisión judicial del contrato. 
específicamente a su contenido. La única alusión al mismo se encuentra en el precepto especial del artículo 2003, puntualmente en su regla cuarta, en que a propósito del rol de la aprobación de la obra por el dueño, el legislador dispone que ella sólo supone que éste la entiende exteriormente ajustada "al plan y a las reglas del arte", sin que exima al empresario de la responsabilidad establecida previamente en la misma disposición. Si bien es cierto que por su ubicación es una regla especial, por lo que inicialmente su ámbito podría entenderse como restringido, creemos que es factible su aplicación analógica por la similar naturaleza de los supuestos de hecho de ambos contratos y la posibilidad de extraer del contrato de construcción a suma alzada una regla general que resulte comunicable ${ }^{43}$.

Siendo así, cabe preguntarse de qué modo esta regla da cuenta de la forma en que se configura la obligación de hacer en estos contratos. La referencia al plan y a las reglas del arte que hace el legislador se puede conectar con el contenido de la obligación que contrae el encargado de ejecutar la obra. De esta forma cabe concluir que la prestación que ha de ejecutarse en estos casos se define en base a dos elementos centrales: lo previsto por las propias partes -es lo que puede entenderse a que alude la expresión "el plan" que emplea la norma-; y junto con ello, por las reglas del arte ${ }^{44}$ de la construcción, es decir, por el conjunto de normas y reglas de carácter técnico y profesional que informan y rigen esa actividad.

Lo primero que determina las características del hacer, en base a la autonomía de la voluntad, es que la obra debe concretarse a partir de lo pactado por las propias partes. El plan o las especificaciones previstas por ellas son, por tanto, la primera pauta a que debe ceñirse el deudor en su ejecución, por supuesto siempre en concordancia con el contenido de la lex artis del área o actividad de que se trate. $Y$ en aquello en que las partes hayan guardado silencio o no hayan regulado con precisión, las reglas del arte cumplen la función ya no simplemente de apoyo a lo convenido por aquellas sino de integrar su declaración de voluntad, para completarla y permitir que se defina el contenido de la prestación del deudor. De esta forma, las reglas del arte vendrían a jugar un rol primeramente de soporte y orientación; y, en segundo lugar, de ser necesario, también de carácter

${ }^{43}$ En este sentido SQuella Narducci, Agustín, Introducción al Derecho (Santiago, LegalPublishing, 2014) p. 676. En similar dirección, Cerdeira Bravo de ManSILLA, Guillermo, Analogía e interpretación extensiva: una reflexión (empirica) sobre sus confines, en: Anuario de Derecho Civil Año 65 (2012) 3, p. 1041.

${ }^{44}$ Díez-Picazo, Luis, cit. (n.4), p. 122, define la lex artis como "el conjunto de específicos reglamentos de la profesión y todo aquello que en la profesión ordinariamente se realiza”. 
supletorio respecto de la voluntad de las partes en relación con el contenido de la prestación.

Si recordamos los dos supuestos fácticos mencionados previamente que corresponden ambos a casos de contratos de construcción- podemos advertir lo que hemos señalado sobre los dos elementos que determinan la configuración de la prestación en estos contratos. En efecto, en el primero de ellos -la refacción de un inmueble antiguo- el plan había sido definido con gran precisión por las partes, a través de un proyecto de arquitectura incorporado al contrato, que fijaba las especificaciones a las que debía sujetarse la ejecución de la obra. De este modo, la lex artis cumplía una función más bien de guía o base a la ejecución por parte del constructor, determinando en conjunto con aquel el contenido de la prestación. En cambio, en el segundo supuesto el plan fijado por las partes era bastante escueto -solamente se había pactado la construcción de una casa y un galpón-, por lo que a las leyes del arte les correspondía completar o llenar los vacíos para definir el alcance de la prestación.

Conforme a lo expresado, la falta de acuerdo o regulación por las partes respecto de las características del hacer y del resultado del mismo, no es óbice para la determinación del contenido de la prestación, pues entonces serán las reglas del arte respectivo las que fijarán los mínimos a que debe ajustarse la conducta de cumplimiento del deudor. A idéntica conclusión llegaríamos aplicando el artículo 1546 del Código civil, al permitir la buena fe objetiva integrar el objeto de la prestación con la lex artis. Así, en el segundo caso presentado, si bien las partes no pactaron más que la construcción de una casa y un galpón, la tarea del intérprete entonces consiste en dilucidar a partir de esta escasa declaración de las partes, el contenido de la obligación asumida por el constructor y habrá de hacerlo recurriendo a los elementos citados ${ }^{45}$.

${ }^{45}$ La sentencia de la Corte Suprema que falla el segundo caso mencionado al inicio de esta sección da cuenta de esta función que cabe a la buena fe $\mathrm{y}$, por su intermedio, a las leyes del arte, para definir el contenido de la prestación. Como las partes solamente habían convenido la construcción de una casa y un galpón, frente a la alegación de un incumplimiento del encargado de la obra, la Corte expresa: "En efecto, aun cuando la parte que encomienda el trabajo no detalle en forma expresa la manera como el contrato debe cumplirse, en esta especial situación debe mirarse al resultado obtenido luego de ejecutada la obra, de suerte que aquella haya quedado en condiciones de servir para lo que es, respetando los principios constructivos y la lex artis que regla la materia" (considerando décimo) y luego agrega, refiriéndose a la buena fe que: "ha de entenderse que el citado artículo 1546 contempla una verdadera norma de integración de los contratos, pues según ella, estos últimos dictan más allá de su letra" (considerando duodécimo). De este modo, el máximo tribunal completa la declaración de voluntad e integra el contrato con las leyes del arte, entendiendo 
Con lo señalado, es fácil concluir que la referencia que la norma aludida hace al plan y las reglas del arte no constituye una regla especial o diversa de aquella que cabría colegir de la aplicación de las reglas generales, por lo pronto, el propio artículo 1546 ya mencionado.

Otra forma de enfrentar la cuestión que se presenta en estos casos sería la de entender que la falta de definición precisa por las partes, de las especificaciones de la actividad a realizar y de la obra resultante, daría lugar a un supuesto de indeterminación del objeto y, por tanto, de falta del mismo, lo que se traduciría en un defecto de validez del contrato ${ }^{46}$. Esta interpretación supone trasladar el problema desde los efectos del contrato y el incumplimiento, al terreno de su celebración y validez. Sin embargo, nos parece que encauzar las dificultades surgidas por la falta de precisión de las partes respecto de la prestación debida al terreno de la nulidad no es el camino más adecuado, desde que habiendo una declaración de voluntad que al menos de modo general da cuenta de lo querido por las partes, es tarea del intérprete completarla y desarrollarla para definir el alcance de lo pactado si surge un conflicto entre los contratantes al respecto, como ocurre en los dos casos descritos, y especialmente en el segundo. La falta de especificaciones detalladas no debería ser un obstáculo para entender

que la obra ejecutada no podía apartarse de las reglas de la construcción, descartando la posibilidad de fundarse en el carácter consensual del contrato y en la ausencia de especificaciones técnicas precisas y claras para dar cumplida una prestación con deficiencias e imperfecciones.

${ }^{46}$ Esto debido a que a partir del artículo $1461 \mathrm{del} \mathrm{CC}$, se afirma que un hecho puede ser objeto de un acto jurídico siempre que sea determinado, requisito cuya ausencia podrá dar lugar a la inexistencia o nulidad de los mismos. Por todos: AlEsSandri, Arturo - Somarriva, Manuel - Vodanovic, Antonio, Tratado de Derecho Civil. Partes preliminar y general (Santiago, Editorial Jurídica de Chile, 2005) 2, p. 257 y $330-331$.

Una tercera forma de enfrentar la dificultad que se presenta cuando las partes no han definido de manera precisa las características del hacer y de la obra convenida, es hacerlo desde la perspectiva de los deberes de colaboración que pesan sobre el acreedor, esto es, de aquel comportamiento que el acreedor debe desplegar para permitir o favorecer la ejecución de la prestación por parte del deudor, el que resulta especialmente importante en contratos que revisten cierta complejidad. Sobre dicho deber, por todos: PRADO, Pamela, La colaboración del acreedor en los contratos civiles (Santiago, Thomson Reuters, 2015). Este punto de vista vuelve la mirada al terreno de los efectos del contrato y su inobservancia -que se produciría en supuestos como el planteado, en que el acreedor que encargó la obra no aportó los datos necesarios para la ejecución por el deudor- podría ser tratada como un incumplimiento de un deber contractual accesorio. Sin embargo, como señalamos, creemos que se trata en rigor de una cuestión de interpretación e integración contractual, y más concretamente, de la obligación que contrae el encargado de ejecutar la obra. 
que hay objeto, otra cosa es la definición de sus particularidades, que si no han sido previstas por las partes de manera explícita o completa, habrán de ser fijadas a través del proceso de interpretación e integración, en que el derecho supletorio, y el llamado a las reglas del arte, cumplirán un rol fundamental. Conviene tener presente que esta es la solución a la que se orienta el moderno derecho de las obligaciones y contratos, la de conducir los eventuales problemas de validez, que en la concepción tradicional puedan presentarse, al ámbito de los efectos del contrato y la discusión acerca del cumplimiento o incumplimiento ${ }^{47}$.

Lo anterior es concordante con el principio de la conservación del contrato, que no es ajeno a nuestro sistema jurídico y apunta precisamente

47 En esta dirección Morales Moreno afirma que una de las consecuencias derivadas de la noción unitaria de incumplimiento -presente en el llamado derecho uniforme de los contratos- es precisamente que "ciertos problemas de validez del contrato son tratados como problemas de incumplimiento y permiten aplicar algunos remedios propios de éste". Así ocurre, por ejemplo, con las cuestiones referidas al error, que pueden perfectamente ser tratadas no como un vicio del consentimiento, sino como un problema de incumplimiento contractual, al no existir coincidencia entre lo pactado y lo ejecutado por el deudor. Esta idea por lo demás es concordante con el principio de la conservación del contrato, que no es ajeno a nuestro sistema jurídico y apunta precisamente a preservar la eficacia y vigencia del acuerdo de las partes, restringiendo las vías por las que ellas puedan afectarse. Morales Moreno, Antonio, Autonomía de la voluntad y responsabilidad en la Convención de Viena sobre compraventa internacional de mercaderias, en Morales Moreno, Antonio, Modernización del derecho de las obligaciones (Madrid, Thomson Civitas, 2006) p. 213. En otra ocasión el autor destaca que una de las posibilidades de apreciar el error es hacerlo no solo como vicio del consentimiento, sino como una forma de incumplimiento contractual, expresando que: "A menudo provoca una alteración en la ordenación de intereses que el mismo [el contrato] establece, que puede afectar a la relación de equivalencia establecida, y suponer un incumplimiento del contrato" Morales Moreno, Antonio, Los vicios de la voluntad en los principios del derecho europeo de contratos, en Morales Moreno, Antonio, Modernización del derecho de las obligaciones (Madrid, Thomson Civitas, 2006) p. 294, agregando que prefiere la solución de los Principios UNIDROIT, en que prevalece el régimen del incumplimiento por sobre el del error, como queda de manifiesto en el artículo 3.7 de dichos principios. En efecto, la disposición que alude el autor, y que corresponde al actual artículo 3.2.4 prevé lo siguiente: "(Remedios por incumplimiento) Una parte no puede anular el contrato a causa de error si los hechos en los que basa su pretensión le otorgan o le podrian haber otorgado remedios por incumplimiento". Por su parte, los PELC van también en la línea de tratar las cuestiones de validez como problemas de incumplimiento contractual. En efecto, en su artículo 4:119 autoriza a las partes que cuenten con acciones para reclamar de la validez del contrato y que puedan deducir también acciones por incumplimiento por las mismas circunstancias, para que hagan uso de cualquiera de dichos medios. 
a preservar la eficacia y vigencia del acuerdo de las partes, restringiendo las vías por las que ellas puedan afectarse ${ }^{48}$.

Finalmente consignamos que en todo caso estamos en presencia de una obligación de resultado, en la que el prestador del servicio se obliga a concretar una cierta transformación en una materia, para dar lugar a una obra que debe ajustarse a un cierto plan y a las reglas del arte. Es indudable que el compromiso asumido por el deudor alcanza o comprende la concreción de dicho resultado materialmente apreciable, que de no verificarse en la forma debida lo ubicará en situación de incumplimiento.

En lo que dice relación con los remedios frente al incumplimiento, y puntualmente, respecto de la obligación de ejecutar la obra, las normas pertinentes son los artículos 1999 y 2002. Ello, sin perjuicio de las reglas especiales ubicadas dentro del artículo 2003.

Respecto a la primera de ellas nos remitimos a lo ya expresado a propósito de los contratos de servicios profesionales, donde también resulta aplicable.

Por su parte, el artículo 2002 dispone que si quien encargó la obra alegare que no se ha ejecutado debidamente - es decir, hay discusión sobre el cumplimiento de la obligación de hacer- debe nombrarse peritos que decidan y si la alegación es fundada, el artífice podrá ser obligado, a elección de quien encargó la obra, a hacerla de nuevo o a la indemnización de perjuicios. En la posibilidad de que el deudor deba "hacerla de nuevo" hay una novedad respecto de lo previsto en las reglas generales acerca de los remedios del acreedor ${ }^{49}$ y que se vincula con una de las dificultades que en general presenta el incumplimiento de las obligaciones de hacer, esto es, la de resolver si el cumplimiento en naturaleza o pretensión de cumplimiento puede traducirse, en tales casos, en lo que en el llamado derecho uniforme se denomina la reparación o sustitución de la prestación defectuosamente ejecutada, es decir, que el deudor corrija lo que hizo mal,

${ }^{48}$ Este principio suele ser empleado para justificar, por ejemplo, que la resolución del contrato no puede proceder si no se está ante un incumplimiento de cierta gravedad o envergadura, por cuanto se debe propender a mantener vigente el contrato, y su extinción por dicha vía debe dejarse para casos extremos. Recoge esta idea Morales Moreno, Antonio, cit. (n.4) p. 45, cuando afirma: "El principio de conservación del contrato impide que cualquier incumplimiento sea causa de resolución. Por eso se hace necesario delimitar qué incumplimientos tienen carácter resolutorio y cuáles no".

49 Tratándose de la legislación especial, existe una manifestación de estos remedios en la ley 19.496 de Protección a los derechos de los consumidores, cuyo artículo 20 contempla la posibilidad para el consumidor de optar por la reparación o reposición -lo que se puede entender como sustitución- del bien en los supuestos de incumplimiento que la norma consagra. 
sea reparando o realizando nuevamente la prestación ${ }^{50}$. Si esta no se ajusta al plan y a las reglas del arte, si no ha sido ejecutada fielmente, entonces, se le exige al deudor hacer lo necesario para subsanar su incumplimiento.

Se trata, como decíamos, de una norma que se distingue de las reglas generales porque dicha modalidad de la pretensión de cumplimiento no está explícitamente prevista en ellas, en tanto están planteadas para supuestos de incumplimiento total y no de los imperfectos o defectuosos y, en ese contexto, lo que contemplan es el derecho del acreedor a pedir que se dé o haga lo debido. Así se desprende del artículo 1553, que regula especialmente los remedios del acreedor en las obligaciones de hacer, contemplando la posibilidad de reclamar la ejecución del hecho, sea por el deudor o por un tercero, es decir, parte de la base de que nada se ha ejecutado. En cambio, lo que el artículo 2002 derechamente prevé, es la posibilidad de exigir que el deudor la realice otra vez. Se pone en el supuesto de que la hizo, pero mal y, por tanto, se le pide que la haga nuevamente y bien hecha. Se recoge en esta disposición la llamada sustitución de la prestación -el remplazo de la mal ejecutada por una nueva, correctamente desplegadacomo una forma del cumplimiento en naturaleza. Dicha posibilidad ha permitido a un autor sostener que este mecanismo de sustitución y junto a él, por ser de menor envergadura, el de reparación de la prestación de hacer defectuosa, sí tienen cabida en nuestro sistema jurídico y pueden ser formas que adopte la pretensión de cumplimiento específico en general en

${ }^{50}$ La reparación y sustitución de la prestación constituyen remedios del acreedor frente a lo que el derecho uniforme denomina falta de conformidad, y corresponden a formas que adopta la pretensión de cumplimiento en aquellos casos en que la prestación es defectuosamente ejecutada. La falta de conformidad es la noción que reemplaza la tradicional figura de los vicios ocultos de los derechos continentales, coincidiendo con aquellos supuestos en que la prestación realizada no reúne las características o cualidades pactadas en el contrato. En tales casos, lo que el acreedor tiene no son las acciones de garantía sino derechamente remedios por incumplimiento que se traducen en pedir la reparación o sustitución de la prestación defectuosa. La figura de la falta de conformidad es una concreción de la noción unitaria de incumplimiento que caracteriza al moderno derecho de contratos y obligaciones. Así lo destaca Morales Moreno, Antonio, Adaptación del código civil al derecho europeo: la compraventa, en Morales Moreno, Antonio, cit. (n.4) p. 45, Modernización del derecho de las obligaciones (Madrid, Thomson Civitas, 2006) p. 97 y ss. Un estudio acabado sobre la falta de conformidad en la compraventa, pero con principios aplicables también a las obligaciones de hacer: Fenoy, Nieves, Falta de conformidad e incumplimiento en la compraventa: evolución del ordenamiento español (Madrid, Centro de Estudios Registrales, 1996) 611 pp. En el terreno puntual de los contratos de servicios, es posible destacar que en los PECL. SC se contempla expresamente esta posibilidad, en los artículos 2:109 y 3:110. 
nuestro derecho ${ }^{51}$. Por otra parte, importante resulta destacar, a efectos de la aplicación práctica de esta regla, lo previsto en el artículo 410 del Código de procedimiento civil en virtud del cual, bastará con que el informe de peritos sea agregado como prueba en el juicio respectivo ${ }^{52}$.

Un comentario aparte cabe hacer respecto de las reglas tercera y cuarta del artículo 2003, que refieren a los remedios frente al incumplimiento. La primera atribuye responsabilidad al empresario -es decir, el deudor del hacer o servicio- en los casos en que el edificio amenace ruina por vicio de la construcción o del suelo que haya debido conocer él o sus dependientes, o por vicios de los materiales (con ciertas particularidades en este último caso según quien los suministró) ${ }^{53}$. Cabe destacar que la norma dice que "será responsable el empresario", sin precisar qué medios concretos de tutela tiene quien encargó la obra en esos casos. Sin embargo, es posible concluir que se trata de la indemnización de perjuicios. En primer lugar, porque la noción de responsabilidad en estricto rigor se identifica con la indemnización de daños porque en esta se materializa la obligación de reparar en que consiste. Luego, se observa la exigencia del requisito subjetivo propio de la responsabilidad: la culpa o negligencia, ya que la aplicación de la norma queda sujeta a que el empresario al menos haya debido conocer los vicios causantes de la ruina. Así las cosas, lo que el artículo 2003 prevé coincide con lo que en la materia son las reglas generales, en la medida que el incumplimiento culpable que causa daños da lugar a la indemnización ${ }^{54}$.

${ }^{51}$ Así lo afirma VIDAL, Álvaro, La pretensión de cumplimiento específico y su inserción en el sistema de remedios por incumplimiento en el Código Civil, en CORRAL, Hernán - Rodríguez, María Sara, Estudios de Derecho Civil II (Santiago, LexisNexis, 2007), p. 529. El autor afirma que el artículo 2002 puede estimarse como manifestación de un principio general y servir de fundamento a los remedios de reparación y sustitución en nuestro sistema jurídico para obligaciones de hacer.

${ }^{52} \mathrm{El}$ artículo 410 del Código de Procedimiento Civil dispone: "cuando la ley ordene que se resuelva un asunto en juicio práctico o previo informe de peritos, se entenderán cumplidas estas disposiciones agregando el reconocimiento y dictamen pericial en conformidad a las reglas de este párrafo, al procedimiento que corresponda usar, según la naturaleza de la acción deducida”. Al respecto, Meza BARros, Ramón, cit. (n.25) p. 125, nota 106, expresa que conforme a lo previsto en este artículo, el nombramiento de peritos se agregará al procedimiento que corresponda y por tanto no serán los peritos sino el juez quien decida, a partir de la valoración que haga del informe respectivo.

${ }_{53}$ La particularidad radica en que si los materiales los suministró el dueño, la responsabilidad alcanzará al empresario solamente si se trataba de un vicio que por su oficio el artífice haya debido conocer o que habiéndolo conocido, no haya dado aviso oportuno.

${ }^{54}$ Cabe hacer presente en todo caso, que en nuestro derecho Corral ha sostenido que el régimen de responsabilidad que contempla esta regla legal sería de carácter 
Por último, hay que considerar además que el inciso final del artículo 1996 dispone que este contrato de arrendamiento de obra -como también lo llama el legislador- se sujeta a las reglas generales del contrato de arrendamiento, sin perjuicio de las especiales que conforman el aludido párrafo 8. Lo anterior presenta la necesidad de buscar dentro de esas reglas generales del arrendamiento las normas que no se contienen en el párrafo 8 porque estas primarían por especialidad. Sin embargo, por la naturaleza del objeto del contrato -allá se trata de entregar una cosa- aquellas que dicen relación con el contenido de la obligación no resultan útiles. A lo sumo, podemos agregar la obligación de garantía que allí cuenta con regulación especial, mas su remisión no es imprescindible por tratarse de un elemento de la naturaleza de todo contrato oneroso. $\mathrm{Y}$ en lo que concierne a los efectos del incumplimiento, no se trata de normas que resuelvan cuestiones problemáticas puntuales de esta clase de contratos, sino más bien, al igual que las escasas normas del párrafo 8, van en el camino de conducir a las reglas generales en la materia.

\section{CONCLUSIOnes}

1. Atendida la relevancia que en el tráfico jurídico han adquirido los servicios, y habida cuenta de la atipicidad que caracteriza a los contratos que recaen sobre ellos, resulta necesario precisar el derecho supletorio aplicable, sin que sean suficientes las remisiones genéricas a las normas del arrendamiento y el mandato que la doctrina y jurisprudencia nacionales suelen realizar al respecto.

objetivo, pues no jugaría rol alguno el dolo o la culpa del deudor, entendiendo que el criterio de atribución sería el vicio. Corral, Hernán, Responsabilidad civil en la construcción de viviendas. Reflexiones sobre los regímenes legales aplicables a los daños provocados por el terremoto del 27 de febrero de 2010, en RCHD. 37 (2010) 3, p. 460. Por su parte, sosteniendo una interpretación que afirma la culpa como criterio de atribución: COURT, Eduardo, Algunas consideraciones en torno a la responsabilidad civil por vicios de la construcción en las legislaciones de España y Chile, en AA.VV., Estudios de Derecho Privado. Libro Homenaje al profesor Gonzalo Figueroa Yáñez (Santiago, Editorial Jurídica de Chile, 2008) pp. 275-308.

Adicionalmente, deben considerarse las dificultades que se presentan para coordinar el artículo 2003 con aquellas disposiciones que en materia de responsabilidad se contienen en la LGUC, concretamente los artículos 18 y 19 de dicho cuerpo legal, pues ha existido discusión acerca de la prevalencia de unas u otras, aunque ello se escapa de nuestro interés desde que los contratos regulados en la LGUC entran más bien en la categoría de los contratos de compraventa, conforme a la regla del artículo 1996, y por tanto, será ese el supuesto de posible colisión, y no aquel en que el contrato de obra queda bajo las reglas del arrendamiento. 
2. La revisión de las normas del contrato de arrendamiento de servicios inmateriales y de ejecución de obra material, así como las del mandato, no permiten construir un régimen legal supletorio propio para los contratos de servicios, al menos en lo que refiere al contenido de las obligaciones y a los remedios del acreedor frente al incumplimiento.

3. En lo que concierne a los servicios profesionales, las normas del mandato y del arrendamiento resultan compatibles a partir de lo previsto en el propio Código civil, sin que pueda afirmarse la exclusión de las primeras.

4. Las disposiciones especiales que regulan expresamente el contenido del servicio y los remedios por su incumplimiento, reiteran las reglas generales contenidas en el Libro IV del Código civil o nos reconducen a ellas. Los únicos preceptos que contienen normas que se apartan de las reglas generales y que pueden contribuir a enfrentar las particularidades de los contratos de servicios son las referidas al desestimiento o terminación unilateral del contrato - aunque con soluciones diversas- y a la sustitución de la prestación defectuosa.

5. Queda por dilucidar si la aplicación de las normas generales, a las que las especiales se remiten o reiteran, son adecuadas para hacerse cargo de las particularidades que presentan los contratos de servicios, especialmente si se tiene en cuenta que la mayoría de ellas están pensadas para obligaciones de dar y no de hacer.

\section{BiBLIOGRAFÍA}

Alessandri, Arturo - Somarriva, Manuel - Vodanovic, Antonio, Tratado de Derecho Civil. Partes preliminar y general (Santiago, Editorial Jurídica de Chile, 2005) 2. АмоRтH, Giorgio, Errore e inadempimento nel contratto (Milano, Giufrè, 1967).

Barendrecht, Maurits - Jansen, Chris - Loos, Marco - Pinna, Andrea - Casçao, Rui - Van Guljo, Stéphanie, Principles of European Law-Service Contracts (PEL SC) (Munich, Sellier European Law Publishers, 2007).

BARRos BourIE, Enrique, Los contratos de servicios ante la doctrina general del contrato: la virtualidad analógica de las reglas del mandato, en ElORRIAGA, Fabián (editor), Estudios de Derecho Civil VII (Santiago, Abeledo Perrot, 2012).

BRANTT, María Graciela, El caso fortuito y su incidencia en el derecho de la responsabilidad civil contractual (Santiago, Abeledo Perrot, 2010).

CAPRILE Biernmann, Bruno, El desistimiento unilateral o renuncia: una especial forma de extinción de los contratos, en Figueroa, Gonzalo et al. (editores), Estudios de Derecho civil VI (Santiago, Abeledo Perrot, 2011).

Cerdeira Bravo de Mansilla, Guillermo, Analogía e interpretación extensiva: una reflexión (empírica) sobre sus confines, en: Anuario de Derecho Civil Año 65 (2012) 3.

CORRAL, Hernán, Responsabilidad civil en la construcción de viviendas. Reflexiones sobre los regímenes legales aplicables a los daños provocados por el terremoto del 27 de febrero de 2010, en RCHD. 37 (2010) 3.

COURT, Eduardo, Algunas consideraciones en torno a la responsabilidad civil por vicios 
de la construcción en las legislaciones de España y Chile, en AA.VV., Estudios de Derecho Privado. Libro Homenaje al profesor Gonzalo Figueroa Yánez (Santiago, Editorial Jurídica de Chile, 2008).

Díez-PicAzo, Luis, Fundamentos de Derecho Civil Patrimonial (6a edición, Madrid, Editorial Civitas, 2008) II.

Domínguez, Carmen, Naturaleza y fundamento de la responsabilidad civil del profesional liberal, en Anales Derecho UC. Temas de responsabilidad civil 1(2006).

Fenoy, Nieves, Falta de conformidad e incumplimiento en la compraventa: evolución del ordenamiento español (Madrid, Centro de Estudios Registrales, 1996).

Guzmán Brito, Alejandro, Derecho Privado Romano (Santiago, Editorial Jurídica de Chile), II.

Jordano Fraga, Francisco, Obligaciones de medios y de resultado. (A propósito de alguna jurisprudencia reciente), en Anuario de Derecho Civil 44 (1991) 1.

López Santa María, Jorge, Los contratos. Parte general (Santiago, Abeledo Perrot, 2010).

Mantilla, Fabricio, El contrato de prestación de servicios médicos en el derecho colombiano, en GuZMÁn BRITO, Alejandro (editor), Colección de estudios de derecho civil en homenaje a la profesora Inés Pardo de Carvallo (Valparaíso, Editorial Universitaria de Valparaíso, 2008).

Mejías Alonzo, Claudia, El incumplimiento resolutorio (Santiago, Abeledo Perrot, 2011).

Meza Barros, Ramón, Manual de Derecho civil, de las fuentes de las obligaciones (9a edición, Santiago, Editorial Jurídica de Chile, 2010) I.

Morales Moreno, Antonio Manuel, La evolución del concepto de obligación en el derecho español (2007), ahora en Morales Moreno, Antonio Manuel, La modernización del derecho de obligaciones (Madrid, Editorial Aranzandi, 2006).

Morales Moreno, Antonio, Autonomía de la voluntad y responsabilidad en la Convención de Viena sobre compraventa internacional de mercaderías, ahora en MORALES Moreno, Antonio Manuel, Modernización del derecho de las obligaciones (Madrid, Thomson Civitas, 2006).

Morales Moreno, Antonio, Los vicios de la voluntad en los principios del derecho europeo de contratos, ahora Morales Moreno, Antonio Manuel, Modernización del derecho de las obligaciones (Madrid, Thomson Civitas, 2006).

Morales Moreno, Antonio, Adaptación del código civil al derecho europeo: la compraventa, en Morales Moreno, Antonio Manuel, Modernización del derecho de las obligaciones (Madrid, Thomson Civitas, 2006).

Moreno Quesada, Bernardo, Problemática de las obligaciones de hacer, en Revista de Derecho Privado (1976).

OrRego, Juan Andrés, El contrato de arrendamiento (Santiago, Editorial Metropolitana, 2011).

Peñailillo Arévalo, Daniel, Responsabilidad contractual objetiva, en Pizarro Wilson, Carlos (editor), Estudios de Derecho Civil IV (Santiago, Editorial LegalPublishing, 2009).

Peñailillo, Daniel, Obligaciones (Santiago, Editorial Jurídica de Chile, reimp. 2011). Pizarro Wilson, Carlos, La culpa como elemento constitutivo del incumplimiento en las obligaciones de medio o de diligencia, en Revista de Derecho Pontificia Universidad Católica de Valparaíso 31 (2008). 
Pizarro, Carlos, El contrato médico. Calificación, contenido y responsabilidad, en RCHD. 41 (2014) 3.

Prado, Pamela, La colaboración del acreedor en los contratos civiles (Santiago, Thomson Reuters, 2015).

Rodríguez Guitián, Alma, El desistimiento en el contrato de servicios de los profesionales liberales, en Anuario de Derecho civil 54 (2001) 2.

Rodríguez Pinto, María Sara, Incumplimiento y exoneración de responsabilidad en los contratos de servicios, en GUZMÁN BRITO, Alejandro (editor), Estudios de derecho civil III (Santiago, LegalPublishing, 2008).

Rodríguez Pinto, María Sara, Responsabilidad por incumplimiento de contratos de servicios, en RCHD. 42 (2014) 3.

SAN MARTín, Lilian, Algunas consideraciones sobre el contrato para la confección de obra material. Problemas derivados de su configuración típica, en VIDAL, Álvaro et al. (editores), Estudios de Derecho Civil X (Santiago, Thomson Reuters, 2015).

SCANTANELli, Néstor, El comercio de servicios. Cuestiones principales desde una perspectiva latinoamericana, en Revista Jurídica de Buenos Aires I-II-III (1997).

SEVERÍn Fuster, Gonzalo, Los contratos de servicios: su construcción como categoría contractual, y el derecho del cliente al cumplimiento especifico (Tesis doctoral [inédita], Universidad Autónoma de Madrid, 2014).

SQuella Narducci, Agustín, Introducción al Derecho (Santiago, LegalPublishing, 2014).

StiTChKIn Branover, David, El mandato civil (5a edición, Santiago, Editorial Jurídica de Chile, 2008).

Villanueva Lupión, Carmen, Los Servicios como objeto de tráfico jurídico (Madrid, Editorial la Ley, 2009).

VIDAl Olivares, Álvaro, La construcción de la regla contractual en el derecho civil de los contratos, en Revista de Derecho Pontificia Universidad Católica de Valparaíso $21(2000)$.

VIDAL, Álvaro, La pretensión de cumplimiento especifico y su inserción en el sistema de remedios por incumplimiento en el Código Civil, en CORRAL, Hernán - RODRÍGUEZ, María Sara, Estudios de Derecho Civil II (Santiago, LexisNexis, 2007).

VIDAL Olivares, Álvaro, Incumplimiento y atribución de responsabilidad en las obligaciones de medio y resultado (a propósito de una sentencia de la Corte Suprema Nro. de ingreso 1771-2007), en Departamento de Derecho Privado Universidad De Concepción (coordinador), Estudios de Derecho Civil V (Santiago, Abeledo Perrot, 2010).

VIDAl Olivares, Álvaro, El incumplimiento de obligaciones con objeto fungible y los remedios del acreedor afectado. Una relectura de las disposiciones del Código civil sobre incumplimiento (2007), ahora, en VIDAL Olivares, Álvaro, Incumplimiento contractual, resolución de indemnización de daños (Bogotá, Editorial Universidad del Rosario, 2010).

Vidal Olivares, Álvaro - BrantT, María Graciela, Cumplimiento e incumplimiento y responsabilidad del deudor en el Código civil. A propósito de la sentencia de la Corte Suprema de 7 de septiembre de 2010, en Revista de Derecho Universidad Católica del Norte 19 (2012) 1.

Vidal Olivares, Álvaro - BrantT, María Graciela, Obligación, incumplimiento y responsabilidad civil del mandatario en el Código Civil chileno, en RCHD 40 (2013) 2. 
